\title{
Entrevista a François Xavier Guerra
}

\author{
Marcela Ferrari, Julio C. Melon \\ y Elis a Pastoriza \\ CEHIS-UNIVERSIDAD NACIONAL DE MAR DEL PLA'TA
}

\begin{abstract}
En octubre de 1995 el doctor François Xavier Guerra visitó la Universidad Nacional de Mar del Plata, donde dictó un seminario sobre el tema "Introducción a la Nueva Historia Política”. Tres investigadores de esa casa conversaron con él y resultó el siguiente testimonio, referido a la experiencia profesional del historiador y a su vinculación con la producción académica.
\end{abstract}

Doctor Guerra, nos gustaría que nos hablara de los comienzos de su carrera como historiador

Mi itinerario es un poco particular, pues de hecho no comencé mis estudios en humanidades sino en ciencias. En aquella época se consideraba que los estudios de humanidades no eran muy rentables económicamente -cosa que sigue siendo verdad. Más valía, si las matemáticas o la física no se le daban mal a uno, ser ingeniero o arquitecto... Esos fueron los estudios que empecé, pero sin demasiado entusiasmo, por eso me pasé primero a geolo- gía y luego, en segundo de carrera, tomé conciencia de que lo que me atraía realmente era la historia. Desde pequeño siempre me había gustado muchísimo y entonces descubrí, en contacto con mis compañeros que estaban cursando historia, que ésa era mi vocación. Aún así estuve dos años cursando paralelamente dos carreras totalmente diferentes, letras y geología. Después me pasé enteramente a la historia, pero pienso que esa formación científica me sirvió bastante, como una escuela de rigor en el razonamiento.

En cuanto a mis estudios de historia en la Soborna de principios de los años 
sesenta, me colmaron totalmente, por la calidad y la variedad de los profesores. El ambiente que reinaba entonces en París era muy estimulante por la variedad de sus enfoques. Lo que dominaba era la historia económica, demográfica y social; dentro de esta última la historia del movimiento obrero estaba en plena pujanza, y por ahí empecé, estudiando el primer periódico marxista francés, L'Egalité, de Jules Guesde, un periódico que se publicó de 1877 a 1882, época en que el movimiento obrero francés se estaba reconstituyendo después del aplastamiento de la Comuna de París. De ahí saldrá el Partido Socialista Obrero Francés, una de las tendencias más acusadamente marxistas del socialismo francés, liderado por Jules Guesde y Paul Lafargue, uno de los yernos de Marx. Dediqué todo el año 1964-65 a estudiar ese periódico tan interesante. Me di cuenta de que era una fuente magnífica no sólo para estudiar la evolución ideológica del socialismo francés, sino para estudiar cómo se construye un partido y cómo se difunde la nueva sociabilidad obrera, tal como se podía ver por pequeñas noticias del tipo: "de tal ciudad nos escriben que se ha constituido tal agrupación"; "tal sindicato o tal casa del pueblo se ha abierto en...". Los restos de ideología libertaria del periódico, sus polémicas con los anarquistas y con otras tendencias socialistas, me llevaban también a valorar la pluralidad de los grupos y de las culturas obreras.

Razones personales me llevaron después a Grenoble. Allí hice ciencias políticas porque me interesaban como complemento para la historia. Empe- cé también a trabajar en una tesis doctoral sobre "Los anarquistas españoles y la Internacional Comunista" con Pierre Broué, un historiador especialista en el movimiento comunista internacional y especialmente en el trotskismo. Hacía unos seminarios apasionantes sobre Rosa Luxemburgo, Boukarin, Trotsky, sobre las luchas de tendencias dentro de la Internacional Comunista, sobre los anarquistas, etcétera.

\section{¿En qué fecha fue esto?}

La época de Grenoble es de los años 65-68. Después de mayo del 68 pasé la "agregación". Es una originalidad francesa, pues es una oposición para ser profesor de liceo, pero al mismo tiempo la única oposición en historia que existe en Francia. Es una oposición muy dura, nacional, con muchos candidatos que concursan para muy pocas plazas (cerca de dos mil candidatos para unas cien plazas). A pesar de que la preparación es pesada, es interesante porque se aprende a trabajar rápido, a preparar, por ejemplo, en siete horas una exposición de 45 minutos. A mí me tocó hablar en uno de los orales sobre los mongoles en el siglo XIII, tema que ignoraba por completo antes, pero con siete horas y libros se puede hacer mucho... Es una oposición arriesgada, pues se puede trabajar durante uno o más años y no sacar nada. Ese sistema sigue existiendo y los mejores alumnos de historia siguen pasando la agregación, no sólo para obtener un puesto de trabajo, sino porque después de entre los "agregados" se reclutan, de hecho, los que 


\section{SECUENCIA}

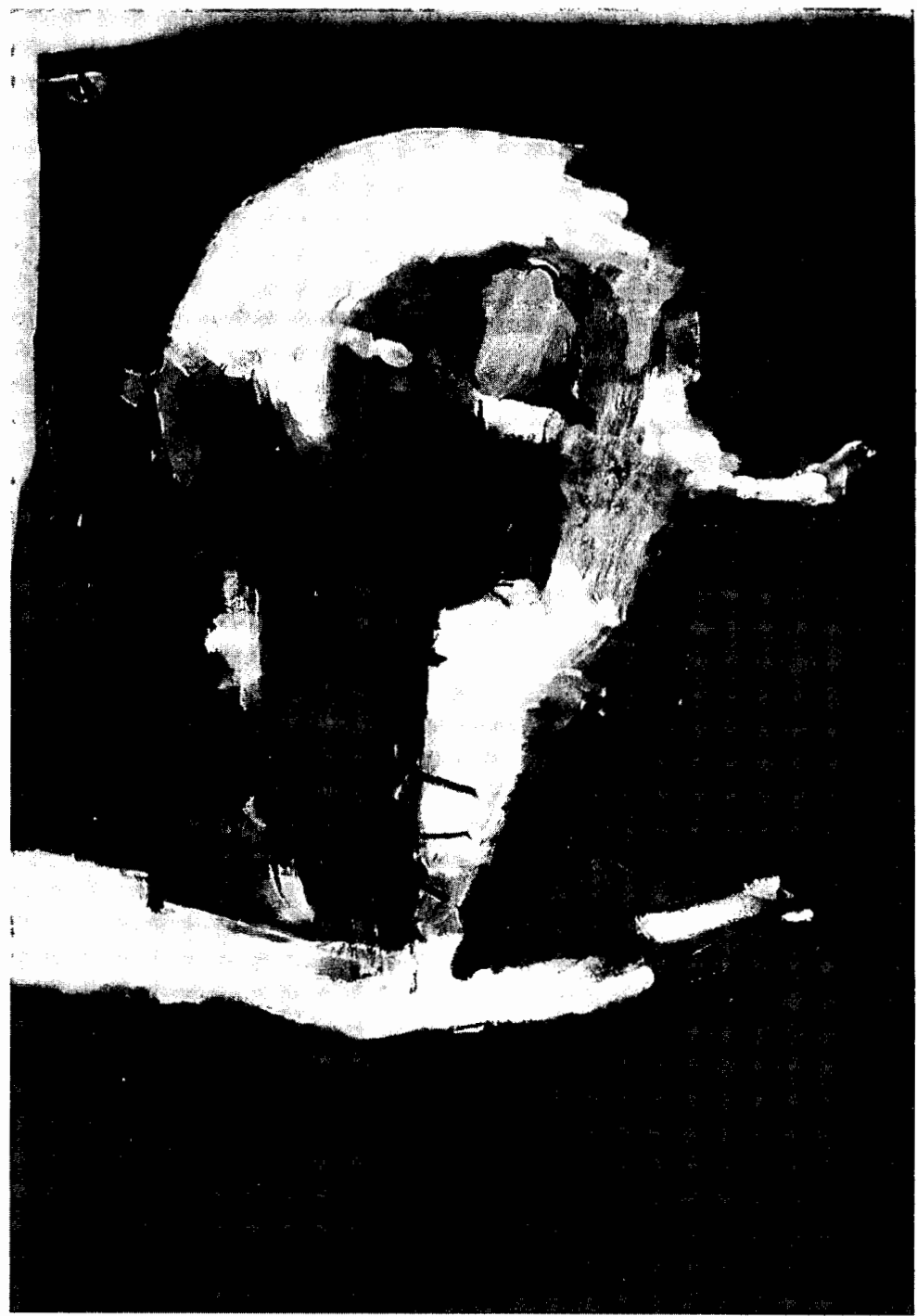

Ilustraciones de Sandra Pani. Queda estrictamente prohibida la reproducción total o parcial de las imágenes publicadas en este número de la revista Secuencia, 37.

Las imágenes fueron contratadas y/o donadas de forma exclusiva para esta publicación. 
van a hacer una carrera universitaria. Ésta es una de las especificidades del sistema educativo francés.

¿Se selecciona también de acuerdo a la capacidad docente?

No. Sólo por conocimientos y por la capacidad de exponerlos de una manera coherente; no se sabe nada de las cualidades pedagógicas del futuro docente.

\section{¿Tienen peso los antecedentes?}

No, ninguno debe entrar en consideración. Los escritos son totalmente anónimos y en ellos son eliminados $80 \%$ de los candidatos.

Entonces, más allá de sus aspectos traumáticos, tiene una pretensión de objetividad muy grande.

Es muy objetiva en una óptica puramente intelectual: doble corrección independiente de los escritos y ejercicios públicos en los orales. No hay ni clientelismo ni amiguismo... Lo que sí puede intervenir es la suerte y también lo psíquico, para aguantar la tensión nerviosa. Además de la agregación hay otra oposición un poco menos difícil, el CAPES (Certificado de Aptitud al Profesoradode Enseñanza Secundaria), con más puestos y también más candidatos; en general los estudiantes de historia concurren a las dos oposiciones.

Para situar la historia en Francia hay que tomar en cuenta el considerable número de estudiantes. Únicamente en mi universidad, en París I (una de las tres universidades en que se divi- dió la antigua Sorbona) tenemos 5500 estudiantes de historia (desde los alumnos de primer año hasta los doctorandos y los que preparan la agregación). No todos, desde luego, van a dedicarse luego a la investigación; la salida profesional normal es la enseñanza secundaria, como titulares si han sacado la agregación o el CAPES, o si no, con un estatuto más precario. Además de la enseñanza secundaria, a donde va la mayoría de los estudiantes de historia, otros se dedican a cosas muy variadas: función pública, conservadores de biblioteca, documentalistas, empresas privadas. Francia es una sociedad muy mandarinal, una sociedad fundada en las oposiciones y en los diplomas, en la que la selección es muy precoz. En general, un joven o una joven a los 22 o 23 años tiene ya un futuro profesional casi enteramente marcado, por lo menos negativamente. Aunque no todos los que han sacado oposiciones lleguen a los más altos puestos, es muy difícil que los que no las hayan sacado puedan llegar ahí. Pese a esas duras condiciones, los estudiantes de historia son los que más aprecian sus estudios. Hace dos años se hizo una encuesta entre todos los estudiantes de Francia sobre si estaban satisfechos o no de sus estudios y el primer puesto lo obtuvo historia, con $90 \%$ de satisfacción, después venían medicina, derecho, etcétera.

Esto para ser profesor en la secundaria. ¿Y los interesados en incorporarse a la Universidad?

Funciona con un sistema diferente: por cooptación. Tanto los asistentes

M. Ferrari, J. C. Melon, e. Pastoriza 
antes (ya no existen), como los "maîtres de conférences" y los catedráticos son elegidos por sus pares, por criterios curriculares.

\section{O sea, no hay oposición.}

Ya no. La única oposición es la agregación de la que ya hablamos.

¿Y cómo son los estudios de grado?

Muy libres. No hay asignaturas sino módulos (antes se llamaban certificados y luego unidades de valor), que corresponden a cursos monográficos. Están organizados por periodos históricos: antiguo, medieval, moderno y contemporáneo. A esto se suma la geografia. Todos los historiadores estudian geografia y los geógrafos, historia. La simbiosis entre historiadores y geógrafos es una tradición muy francesa; aunque actualmente se está debilitando sigue existiendo y es muy útil que así sea.

\section{¿Es esto prebraudeliano?}

Sí, es una tradición fundada en la complementariedad entre el tiempo y el espacio.

Nos decía que no hay asignaturas sino "módulos".

Sí. Un estudiante de primer año estudiará por ejemplo en historia contemporánea "La sociedad francesa de 1851 a 1914" y "Los obreros en Francia, Alemania y Gran Bretaña de 1900 a 1970"; y en moderna, "La economía y la socie- dad del Antiguo Régimen (siglo XVIII)". Lo mismo que pasa en la licenciatura, en tercer año. Son siempre temas monográficos. Cabe preguntarse, ¿qué saben del resto de la historia? Si no han escogido nunca o no les ha caído en suerte el estudiar la revolución francesa, ¿cómo conocen la historia de la revolución?

\section{¿Y cuál es la respuesta?}

No es simple... llevamos décadas discutiendo este problema. Se supone que con estos cursos monográficos los estudiantes, por curiosidad intelectual, van leyendo otros libros, llenando ellos mismos los huecos, y que son capaces de hacerlo porque han aprendido a estudiar por sí mismos. Puede suceder que a lo peor, no sepan nada... Probablemente este sistema funciona porque la enseñanza secundaria en Fran. cia, en los buenos liceos, es de calidad y da a los alumnos una formación con una base conveniente.

\section{Nos estaba hablando hace un} momento de su formación, de la crisis de mayo del 68, de Braudel, de la geografia.. Esa coyuntura que vino de la mano de la revalorización del acontecimiento, el redescubrimiento de lo político y de lo cultural, ¿explica la crisis del braudelismo?

Bueno, nunca fui muy braudeliano... Pienso que no solamente Braudel, sino toda una historia estructural muy económica entró en crisis después de mayo del 68 por la irrupción de lo cultu- 
ral y de lo político. En parte por la incapacidad que mostraban esos enfoques para explicar las crisis.

En ese sentido mayo del 68 representó un hito esencial. Fue una crisis totalmente inédita, que empezó de manera inesperada y terminó abruptamente. En unas semanas casi provocó el derrumbe del régimen gaullista disolviendo el poder y la legitimidad del Estado. Se inició con una revuelta estudiantil y culminó en una impresionante huelga general. Curiosamente esta explosión súbita no se dio en un contexto de crisis económica. Eran años, por el contrario, de una expansión sin precedentes en la Francia contemporánea, años de pleno empleo, lo cual cuadraba muy mal con las interpretaciones tradicionales que ligaban los periodos revolucionarios con crisis económicas, con el desempleo, con la pauperización. Otros aspectos extraños de mayo del 68 fueron la importancia de lo cultural-de la palabra, del discurso utópico- y el hecho de que sus principales actores, los estudiantes, no eran grupo social sino generacional y cultural.

La originalidad de este acontecimiento nos llevó a mí y a otros, a reflexionar sobre las categorías explicativas que estábamos usando hasta entonces en historia. Había que buscar herramientas conceptuales nuevas que incluyeran lo político y lo cultural y fuesen capaces de explicar las rupturas, esos momentos que no sólo son como parteaguas de la historia, sino también extraordinarios reveladores de los actores y de los imaginarios de una sociedad. Muchos se cansaron de estudiar la "larga duración", los grandes ritmos, las vastas estructuras y los vastos grupos sociales.

Quizás estos cambios tengan algo que ver con la moda. A lo mejor dentro de diez años volveremos a privilegiar la historia social y económica, o a otro tipo nuevo de enfoque que desplace lo que estamos haciendo ahora...

\section{En su primer trabajo sobre "L'Egalité" usted detectó aspectos del funcionamiento de grupos locales. ¿Esto estaría emparentado con cuestiones que trató anteriormente?}

Sí, ya estaba muy convencido de que había que estudiar los grupos, sus implantaciones, sus diferencias culturales y también de que había que estudiar a los hombres - lo que me llevó después a la prosopografia. Tampoco creía ya que las clases fuesen actores; estaba convencido de que los actores reales eran grupos de otro tipo. En parte esta convicción procedía de mis estudios sobre el movimiento obrero y del enfoque microhistórico al seguir casi día a día los múltiples grupos que iban a conformar el movimiento obrero francés: varios partidos socialistas, diversos grupos anarquistas, sociedades mutualistas, cooperativas, etc. Unificar toda esa gama bajo una única etiqueta de clase obrera era imposible...

\section{¿Hay una influencia del presente en su análisis del pasado?}

Sí, siempre nos ha pasado eso a los historiadores y más a los historiadores 
de historia contemporánea. Nos interesamos por el pasado a partir de los problemas que nos plantea el presente. No digo que vayamos a trasponer lo que sucede ahora al pasado, sería un anacronismo. Pero es evidente que los problemas del presente nos llevan a estudiar determinados temas del pasado o a estudiarlos de manera que puedan explicar lo que nos preocupa o intriga en nuestra época.

¿Usted no considera esto como algo particularmente propio de la historiografia francesa?

Pienso que es general.

\section{¿Y cuándo decidió trabajar sobre México?}

Por los azares de la vida. Una vez que pasé la agregación me fui a hacer el servicio militar. Seguía con la idea de trabajar sobre el movimiento obrero internacional; pero no quería enseñar en la secundaria. Para entrar en la universidad había que encontrar un catedrático que estuviera dispuesto a tomarlo como asistente. Fui a ver a François Chevalier, a quien no conocía, y le manifesté que me gustaría trabajar con él. Me aceptó pero a condición de trabajar sobre América Latina. De ahí que empezase una tesis sobre la revolución mexicana. Fue pues una evolución debida a razones prácticas y en gran parte casuales; hasta entonces América Latina estaba fuera de mis intereses y no sabía nada sobre ella.
El encuentro con Chevalier fue para mí muy importante. Chevalier es un discípulo directo de Marc Bloch, un gran maestro $y$, sin duda, una de las personas que conocen mejor la historia de América Latina. Desempeñó un papel inmenso en el lanzamiento de toda la historia social en América Latina con su tesis sobre la formación de los latifundios en México, que es una obra irreemplazable. Hay en esa obra mucho más que una pura historia agraria; es una historia social en el sentido más pleno de la palabra, en la que entran el estudio de los vínculos sociales, de la mentalidad señorial y muchos elementos de análisis cultural. Las conversaciones que tuve durante esos años con Chevalier fueron muy enriquecedoras y me abrieron los ojos sobre la complejidad de América Latina.

\section{Allí nació el tema de los actores.}

En parte, por sus anotaciones muy pertinentes sobre los clanes familiares o las comunidades indígenas, pero ése no era su tema principal y tampoco lo político. Pienso que la nueva historia política la descubrió con mi tesis y como tiene una gran apertura de espíritu ha integrado estos enfoques en su última gran síntesis sobre América Latina (en la segunda edición muy aumentada de L'Amérique latine de indépendance à nos jours). La conceptualización de los actores reales nació espontáneamente, como una necesidad de explicar los vínculos entre los individuos que encontraba en mi prosopografia del México porfirista y revolucionario. 
$Y$ este concepto que usted ha enunciado como "grupos culturales" o incluso como "clase cultural" para definir a aquellos que fueron el motor de la independencia de Hispanoamérica...

El término "clase cultural" era una provocación para provocar una toma de conciencia, pero es cierto que tengo una noción muy cultural de la casualidad histórica. Para mí lo importante son los grupos mutantes desde el punto de vista cultural. Ellos son los que en un cierto momento elaboran y a veces imponen un modelo social nuevo. Los proyectos de una sociedad nueva son un rasgo característico de los siglos XIX y XX. Claro que cuando Luis XIV intentaba conformar una monarquía centralizada había ahí una tentativa de crear un nuevo modelo de monarquía, pero no creo que intentase crear una nueva sociedad. A partir de la victoria de la modernidad en el siglo XIX, pienso que la periodización histórica hay que hacerla en gran parte según las coyunturas culturales. Por ejemplo, en América se ve muy claramente después de la segunda guerra mundial la existencia de ciclos que involucran a prácticamente todos los países. Hay un ciclo de expansión de mesianismo revolucionario, luego un ciclo de dictaduras militares, cuando se difunden conceptos como la seguridad nacional, en los que toda divergencia política es interpretada como un peligro para la nación y justifica la supresión de los derechos del hombre. Se acaban después las dictaduras militares y se restaura la democracia. Y eso prác- ticamente en todos los países, sea cual sea su situación social o económica. Las coyunturas político-culturales son sin duda tan importantes o más que las económicas.

Lo mismo había pasado en el siglo XIX: a la era de las revoluciones de principios de siglo, sigue la época doctrinaria de los años 1830-40 con sus tentativas de estabilizar los regímenes políticos por la restricción de la ciudadanía, y después de la revolución de 1848 , se produce una nueva radicalización y se impone el ideal del sufragio universal. Después viene a finales del XIX, como en Europa, la época del positivismo, cuando triunfa una nueva manera de pensar la sociedad y se edifican regímenes políticos que, aun siendo formalmente democráticos, dan la prioridad al orden como condición del progreso. Las mismas concordancias de tiempos pueden también constatarse en la expansión del marxismo en los años sesenta de este siglo.

Para entender la política y comprender la evolución social global no se puede prescindir de esas coyunturas político-culturales y del estudio de las mutaciones de las elites culturales. Preciso que con la palabra elites no designo esencialmente una elite económica, sino cultural. Muchas veces se trata de estudiantes de origen modesto o de obreros y artesanos, como ocurrió en la constitución del movimiento obrero. Ellos son quienes provocan la aparición de nuevas sociabilidades y los que formulan nuevos proyectos sociales.

Para volver a la época de la independencia, lo esencial de este periodo es 
además de la independencia propiamente dicha, la invención y la instauración de la política moderna: la proclamación de la soberanía del pueblo, la definición del ciudadano, la necesidad de elecciones para legitimar el poder... Cuando se examina quiénes fueron los autores de estas mutaciones se ven patricios, clérigos, abogados, funcionarios, estudiantes. Sus rasgos comunes son el pertenecer a una elite cultural y no sus características económicas. No se ve por ningún sitio una nueva burguesía, aunque en Buenos Aires haya bastantes comerciantes implicados. Llamar burguesía a los mantuanos - a una aristocracia esclavista- o a clérigos mexicanos como Hidalgo o Morelos, me parece un abuso de lenguaje. Como no se les puede caracterizar socialmente y son, por el contrario, muy homogéneos culturalmente -hablo de "clase cultural" aunque no sea una clase, sino un medio social-, lo que tienen en común es que imaginan la sociedad de una manera análoga y comparten prácticas culturales semejantes. No hay que olvidar lo económico, pero dando a lo económico sudimensión política. Ciertamente la lucha por la libertad de comercio y en contra del monopolio de Cádiz fue importante pero incluso más por sus implicaciones ideológicas que prácticas. El rechazo por los peninsulares de la libertad de comercio, en una época en que triunfaba el liberalismo económico, era visto por los americanos como opresión política -negación de su igualdad con los españoles- y como voluntad de mantenerlos fuera del progreso de la civilización.
Su preocupación por la historia política se ha visto convalidada por las últimas tendencias en el quehacer histórico. ¿Cómo imagina el panorama de la historiografía en relación con esta revalorización?

Cuando hablo de historia de "lo político" me refiero de hecho a una historia tendencialmente global. No estoy aludiendo solamente a quién ganó unas elecciones o a por qué las ganó. Este tipo de estudios es interesante pero de importancia limitada. Lo que me interesa es entender la dinámica global de la sociedad y pienso que es por lo político y lo cultural por donde se puede explicar el paso de un tipo de las sociedades del Antiguo Régimen a las so-ciedades modernas y los problemas que eso crea. Para mí la historia política es una historia que tiende a la globalidad e incluye los otros aspectos, incluidos los económicos, que tienen también un fuerte componente cultural: invenciones técnicas, imaginarios económicos, modas conceptuales, por ejemplo.

\section{O sea que para usted esta "historia política" implica para el historiador la posibilidad de recuperar una globalidad mayor incluso, más comprensiva...}

Por ejemplo, la posibilidad de explicar la aparición de los nuevos países en América, la invención de la nación y los traumatismos que esto implica, corresponden a una historia de tipo global que condiciona también lo económico. ¿Qué es la independencia? La 
independencia es, evidentemente, un acontecimiento político, porque hay que fundar Estados y naciones, constituir autoridades con una nueva legitimidad, pero también es un fenómeno clave para la economía: un fenómeno de tipo coyuntural y no estructural. Para la mayoría de los países hispanoamericanos la independencia supone una catástrofe económica de primera magnitud, de la que América (y también España) tardarán prácticamente tres cuartos de siglo en recuperarse parcialmente. ¿Cómo hacer entonces una historia económica del siglo XIX dejando de lado este acontecimiento clave y fundador?

\section{Cómo explicar la construcción si no se conoce la destrucción...}

Exactamente. ¿Cómo hacer una historia económica de México en el siglo XIX si se ignora, por ejemplo, que en la guerra de Independencia pierde quizás $10 \%$ de la población total y $50 \%$ de la población activa? $O$ sin considerar el problema de descapitalización provocado tanto por envíos de plata a la metrópoli para sostener las guerras de la época revolucionaria, como por la destrucción de las minas durante la guerra en Nueva España, esas minas de plata mexicanas que eran la base del sistema monetario internacional. México, al acabar la guerra de la Independencia no tiene capital. Antes era él quien suministraba capital a toda la monarquía y a buena parte de la economía internacional, después tiene que ir a buscar capitales al extranjero. Si no se consideran rupturas políticas de este calibre, los análisis estructurales se ven reducidos a extrapolaciones sin fundamento.

Lo mismo pasa con la educación. Cuando se consideran los índices tan altos de analfabetismo del último tercio del XIX, la historia clásica de la educación razona por extrapolación regresiva: "si entonces hay $20 \%$ de alfabetizados eso quiere decir que a finales del siglo xviI deberíamos tener muchos menos". Seguramente no es así. Hay estudios monográficos que muestran que hay más escuelas en México a finales del xviI que a mediados del XIX. El fenómeno es perfectamente normal, puesto que aquellas escuelas se mantenían sobre todo con recursos comunales, corporativos o de cofradías. Era lógico que tanto la ruina económica de muchos pueblos como las leyes liberales que atacaron las instituciones y los bienes comunales y corporativos, produjesen la decadencia de la educación antigua antes de que el Estado reconstruya una nueva. Lo mismo ocurrió en la Francia posrevolucionaria. En síntesis, creo que muchas de las periodizaciones del siglo XIX, en América y seguramente también en Europa, tienen que ser revisadas a partir de estos acontecimientos políticos fundadores.

¿Qué posibilidades explicativas ofrece al historiador el análisis de las rupturas? ¿Hay una revalorización del acontecimiento de corta duración?

Las rupturas son ante todo acontecimientos que se sitúan en la corta dura- 
ción, como los que han precipitado, por ejemplo, la caída del imperio soviético. Siempre se puede decir a posteriori que detrás de ellos hay causas estructurales, pero lo cierto es que a la mayoría de los observadores les toman totalmente por sorpresa. Cuando empezaron las manifestaciones en Alemania del Este, que fueron el principio del fin del imperio soviético, todo el mundo se quedó asombrado. Había muy poca gente-realmente muy poca- que preveía la caída del sistema soviético. Al contrario, la mayoría de los estudios insistían sobre su extraordinaria estabilidad. Incluso disidentes rusos como Zinoviev llegaban a decir que el hombre es naturalmente soviético, en la medida en que los vicios evidentes del sistema estaban compensados por el hecho de que el Estado se ocupaba de todo, de que la gente trabajaba lo menos posible y no estaba sometida a una competencia incesante, etcétera.

Tengo que reconocer que su caída no me tomó demasiado por sorpresa. Siempre me interesó Rusia y estaba convencido, por mi estudio de la revolución mexicana, de que los regímenes políticos no pueden subsistir cuando funcionan de manera opuesta a los principios que los fundan. Cuando un régimen se funda en la soberanía del pueblo, o en el proletariado, o en las masas, y al mismo tiempo viola sin cesar esa legitimidad, acaba por desintegrarse.

Violan su propia legitimidad...

Así es. A mí lo que me entusiasmó de los acontecimientos de Alemania del
Este fue el grito de los manifestantes de Dresde: "Nosotros somos el pueblo". El rechazo del régimen se fundaba explícitamente en el principio de base de la legitimidad moderna.

\section{Estábamos en la visión del}

acontecimiento como algo ligado a los momentos de ruptura.

No todo acontecimiento tiene trascendencia social, pero sí algunos. ¿Cómo definir los periodos revolucionarios? Son periodos en los que el acontecimiento es rey, es decir, aquellos en los que el tiempo corto es esencial. Normalmente los acontecimientos no cambian gran cosa. Hay manifestaciones que no modifican la historia de un país. Pero hay momentos en que una manifestación (como en mayo del 68), cambia fundamentalmente la situación. Son momentos en que la sociedad está como suspendida en el vacío y esos momentos aparecen muy ligados a crisis de legitimidad del poder, como las manifestaciones en Alemania del Este a las que aludíamos antes. Eso son las épocas revolucionarias: periodos en que los acontecimientos modifican radical e irreversiblemente la situación.

\section{Al respecto es claro que en una revolución no se resuelve el carácter fundacional \\ de un nuevo orden...}

Por lo menos permite ver cómo se cae un sistema carcomido. Ahí es donde salen a la luz los verdaderos actores, sus referencias culturales, el funciona- 
miento real del sistema político, las premisas en las que está asentado. Pero, claro, eso se ve a posteriori, cuando ya los actores han entrado en acción.

En cuanto a la memoria histórica, ¿nota diferencias entre Europa y América?

Es evidente que en Europa -no sé cómo perciben esto aquí- la historia está mucho más presente, hasta físicamente, por los monumentos. Hay como una impregnación física de la historia, que se puede incluso observar en el discurso de los hombres políticos. En Francia, por ejemplo, los acontecimientos del siglo XIX, la revolución francesa y en general toda la historia de Francia son una de las claves del discurso político. Los discursos de De Gaulle estaban llenos de invocaciones históricas, tanto a la época revolucionaria como a la Francia del Antiguo Régimen, a una Francia eterna. Lo mismo pasa con Mitterrand, que utiliza también esos recursos oratorios. Me acuerdo que en la campaña presidencial de 1965, al hablar después de De Gaulle en la campaña televisiva, comenzó su intervención diciendo: "Esta voz que acaban de oír es la voz de 18 brumario, es la voz del 2 de diciem. bre... es la voz que anuncia el fin de la república". El 18 brumario se refería evidentemente a la toma de poder por Napoleón y el 2 de diciembre al golpe de estado de Luis Napoleón Bonaparte que puso fin a la segunda república. Los europeos estamos inmersos en la historia, y apelar al pasado legitima $o$ deslegitima las acciones presentes.
Digamos que la contemporaneidad de los franceses coincide con la "historia contemporánea" e incluso con el lenguaje venerado por esta historia.

La historia como construcción historiográfica es en todos los sitios un elemento clave de los imaginarios sociales y una puesta en escena de valores. De ahí que muchos combates ideológicos se expresen en combates históricos y también que la pacificación ideológica acabe por modificar la historia. Eso fue lo que decía Furet, cuando habló de "enfriar" la revolución francesa y hacer de ella un objeto histórico normal y no un signo de pertenencia a un campo ideológico. Por eso dijo que la revolución francesa había terminado.

Esto remite al problema político que significó esta reconsideración de la revolución

Efectivamente, la reevaluación de la revolución fue paralela a la disminución de las divisiones ideológicas y al acercamiento de los programas de los partidos políticos. ¿Cuál es la causa y cuál es la consecuencia? Son sin duda fenómenos correlativos que propician una política mucho más consensuada y menos apasionada.

Es interesante esa continua interrelación pasado-presente que, si bien no es algo particularmente francés, impregna a Francia...

Aunque ocurra en todos los sitios, es algo más acusado en países en los que

M. Ferrari, J. C. Melon, e. Pastoriza 
los Estados-naciones son la continuación de reinos con una larga historia. En Europa hay pocos países en los que una nación en el sentido cultural coincida con una unidad política secular. De hecho hay sólo tres: Francia, Inglaterra y Castilla (y no España, que es de composición más tardía). En los otros países, el recurso al pasado es más difícil, pues tienen que disociar lo político de lo cultural; pensemos en Alemania, o en Italia. Aunque todas las naciones son inventadas, algunas fueron inventadas antes y eran más homogéneas cuando las otras se constituyeron. Por eso, aunque toda historia nacional tiene una parte de mito, esa parte es aún mayor en comunidades humanas que estuvieron dispersas en varios estados o que fueron integradas en cierto momento en otros más vastos. En todos esos casos, la referencia a la historia es más incierta, puesto que es dificil hacer una construcción lineal de la nación. Los catalanes, para tomar un ejemplo en España, al reivindicar su identidad nacional tienen que acudir a la historia de la edad media, borrar siglos enteros de unión pacífica con la corona de Castilla o exaltar algunos momentos de crisis en su relación con ella.

El concepto de nación, de alguna manera se ve modificado por sucesos actuales como la virulencia del conflicto yugoeslavo, a sabiendas de que estamos hablando de cosas distintas...

Es curioso ver cómo a veces el interés de los historiadores precede a los acon- tecimientos. Muchas de las obras importantes sobre la nación, como las de Anderson, Gellner, o Hobsbawm son anteriores a la caída del imperio soviético o a la desagregación de Yugoslavia. Mis primeros seminarios sobre la nación datan también de los años ochenta. En este caso nuestro interés por el problema de la nación precedió al resurgimiento actual de los problemas nacionales. ¿Por qué? Es dificil responder, quizá fuese una intuición o el agotamiento de otras temáticas. En mi caso, fue la consecuencia lógica de mi interés por el surgimiento de la modernidad. El estudio de la revolución mexicana me había conducido a pensar que los elementos explicativos claves de la América Latina contemporánea había que buscarlos en la época de la independencia, pues ahí aparece ese desfase esencial entre la política moderna por un lado, y el carácter tradicional de la sociedad por otro. Aunque conceptualmente la independencia y la revolución sean dos cosas diferentes, las dos son de la misma época.

\section{Ahora, si estas naciones modernas se ven tan impregnadas por elementos tradicionales, ¿es válido conservar la dicotomía tradicional/moderno?}

Pienso que es legítimo. Cuando en la edad media los reyes de Francia y sus consejeros, clérigos y letrados, construyen una historia antigua del reino, inventan ceremonias y símbolos, o imponen después en 1539 el francés como la lengua oficial en todo el rei- 


\section{SECUENCIA}

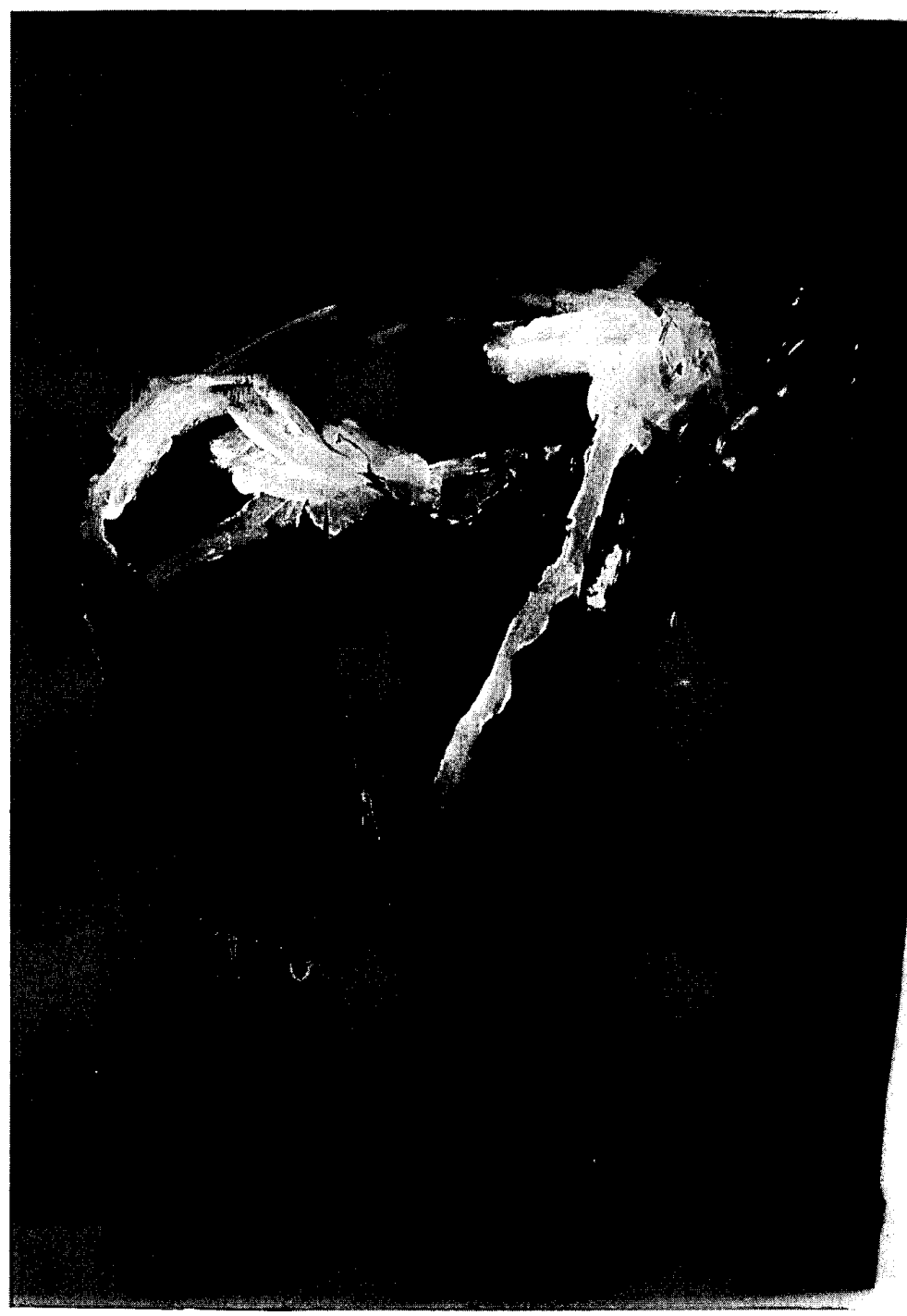


no, está claro que están llevando a cabo políticas culturales que tienden a crear una comunidad unificada. Aunque estas iniciativas tengan analogías con la construcción de la nación francesa después de la revolución, no se fundan evidentemente en los mismos principios. Distinguir ahí entre la construcción de la nación antigua (el reino) y la moderna es una manera de no caer en anacronismos...

\section{¿Qué piensa de las prácticas historiográficas encuadradas en procedimientos tales como la prosopografia?}

La prosopografia es un instrumento importantísimo, fundamental para salir de los lugares comunes. Por ejemplo, cuando Pilar González Bernaldo hizo la prosopografía de la clase política rosista, cayeron una serie de ideas preconcebidas sobre un régimen asen. tado en los hacendados. Cierto es que para otros periodos, o grupos, la prosopografia puede ser menos relevante. Hay que tener cuidado con la prosopografia porque es un instrumento muy pesado que exige mucho tiempo para llegar a veces a resultados poco significativos. El trabajo prosopográfico es útil para periodos confusos o para periodos cruciales, para examinar quién ejerce realmente el poder y acabar así con caracterizaciones poco fundadas.

\section{¿Y en cuanto a la microhistoria, procedimiento muy extendido en los últimos años?}

Me parece una vía muy interesante pero sin olvidar temas más importantes. Po- demos ciertamente hacer la microhistoria de un pueblo de Ucrania y seguramente obtendremos resultados interesantes, pero me parece que es más relevante estudiar por qué se deshizo el imperio soviético. Hay una jerarquía en los temas históricos y aunque puedan hacerse muy brillantes y sofisticados estudios de temas menores, no deben abandonarse los temas fundamentales.

\section{¿Cuál es el lugar que ocupan en Europa los estudios latinoamericanos?}

Un lugar un poco mejor del que tenían antes. Los años sesenta y setenta fueron funestos por la imagen exótica que ofrecían del subcontinente. Latinoamérica aparecía como una región extraña, llena de caciques y caudillos, de pronunciamientos y golpes de Estado, de dictaduras militares y de guerrilleros. Era un mundo singular, con personajes excesivos y situaciones extremas, una delicia para periodistas y ensayistas. Daba la sensación de que muchos investigadores miraban a Hispanoamérica con los ojos de la utopía, como una tierra de experimentación de sistemas explicativos que no osaban aplicar a Europa o a Estados Unidos; o con los ojos de un entomólogo yendo a ver "bichos" un poco raros. Evidentemente, aunque muchos de esos fenómenos extremos se den realmente, eso no quiere decir que Hispanoamérica sea un continente exótico o extraño. Para mí, la comprensión de Hispanoamérica debe partir de lo que es: una parte de América, a su vez, una parte 
esencial de esta área de civilización que se extiende a ambos lados del Atlántico. Ese conjunto europeo-americano, o americano-europeo, es un área de civilización con ritmos culturales y políticos parecidos, con problemas semejantes, más allá de sus diferencias evidentes. La comparación entre ambos continentes es indispensable tanto para entender lo que pasa en un lado como en otro. Para mí y para muchos, el objetivo es precisamente que no haya latinoamericanistas, sino sociólogos, historiadores, geógrafos, politólogos que estudien Hispanoamérica como podrían estudiar Francia,
Italia, España o Estados Unidos, sin olvidar que estamos en la misma área de civilización y que precisamente la originalidad de América sólo se entiende realmente cuando no se la considera como un mundo exótico.

\section{No al "latinoamericanismo"...}

El latinoamericanismo no es una disciplina con métodos específicos. Yo no me considero como un latinoamericanista, sino como un historiador que estudia América Latina... y algunas cosas más. 